
\title{
25 Research Square \\ The Effect of A2E On The Levels of ROS and The Distribution of A2E in RPE Cells Exposed to Blue Light
}

Maomei Luo

Guizhou Eye Hospital, Affiliated Hospital of Zunyi Medical University

Chun Zeng

Guizhou Eye Hospital, Affiliated Hospital of Zunyi Medical University

Shu Wang

Guizhou Eye Hospital, Affiliated Hospital of Zunyi Medical University

Shanjun Cai ( $\nabla$ caishanjun@163.com )

Guizhou Eye Hospital, Affiliated Hospital of Zunyi Medical University

\section{Research Article}

Keywords: N-retinylidene-N-retinylethanolamine(A2E), age-related macular degeneration(AMD), retinal pigment epithelium(RPE), lysosomes

Posted Date: December 3rd, 2021

DOI: https://doi.org/10.21203/rs.3.rs-1098430/v1

License: (9) This work is licensed under a Creative Commons Attribution 4.0 International License. Read Full License 


\section{Abstract}

\section{Aims}

To establish the N-retinylidene-N-retinylethanolamine(A2E) and blue light induced RPE cells damage model to explore the regularity of distribution of $A 2 E$ and the levels of reactive oxygen species(ROS).

\section{Methods}

The fourth to sixth generation of human RPE cells in vitro were divided into five groups randomly: control group, blue light group, A2E-loaded group, A2E-loaed+blue light group and A2E-loaded+blue light +nifedipine group. The levels of ROS in cytoplasm by DCFH-DA staining was assayed by flow cytometry. The concentration of A2E in cytoplasm and lysosomes were assayed by high-performance liquid chromatography-tandem mass spectrometry (HPLC-MS). The fluorescence intensity of A2E in lysosomes by Lysotracker redDND-99 staining was assayed by confocal laser scanning microscope.

\section{Results}

Exposure to blue light and/or A2E could increase the levels of ROS in RPE cells, and nifedipine could inhibit oxidative stress response and reduce ROS levels. By HPLC-MS, it was found that A2E was not detected in the groups without load A2E, and A2E levels in cytoplasm and lysosomes decreased after light exposure. The green fluorescence produced by A2E loaded on RPE cells was mostly coincident with the red fluorescence labeled by lysosomes.

\section{Conclusion}

Blue light and A2E can increase the ROS levels of RPE cells and both have a synergistic effect. A2E is mainly concentrated in lysosomes, which is reduced by oxidation under blue light irradiation, damages lysosomal membrane with oxidized species of A2E, and leaks out from lysosomes.

\section{Introduction}

Age-related macular degeneration (AMD) is a major cause of visual loss in middle-aged and older people ${ }^{1}$

2. The exact cause of this disease remains unknown. Unfortunately, there is no effective AMD treatment or method of prevention, except the avoidance of blue light.

Retinal pigment epithelial (RPE) cells can regenerate; synthesize retinal pigments; repair photoreceptors and Bruch's membranes; transport oxygen, water, ions and nutrients from the choroid vessels to the outer retina; phagocytose; and degrade photoreceptor outer membrane discs ${ }^{3}{ }^{4}$. When the devoured membrane discs are not completely digested in the lysosome, the residues accumulate to form lipofuscin.

$\mathrm{N}$-retinylidene-N-retinylethanolamine (A2E), the main fluorescent substance of lipofuscin, consists of alltrans retinol and ethanolamine 『is phototoxic and deposited in RPE cells with age ${ }^{5}$. The etiology and 
pathogenesis of $A M D$ are associated with $A 2 E^{5}{ }^{6}$, increasing evidence shows that $A 2 E$ is the most abundant toxic substance in lipofuscin ${ }^{7}$. In the absence of blue light, low concentrations of A2E do not cause apoptosis in RPE cells, but A2E can trigger apoptosis when it accumulates over the physiological dose $^{8}$. In addition, exposure to blue light can accelerate the oxidation of RPE cells by A2E, inducing oxidative stress and apoptosis ${ }^{9-11}$. Zhao $Z$ showed that exposure to blue light increased the levels of GRP78, CHOP, P-JNK, and Bax and the cleavage of Caspase 3 and Caspase 9, which eventually triggered apoptosis in RPE cells containing $\mathrm{A}^{2} \mathrm{E}^{10}$.

Since A2E and blue light are closely related to the occurrence and development of AMD囚the members of this group have explored the best conditions to develop an RPE cell injury model in blue light: an optimal blue light intensity of $2000 \pm 500$ lux, a $6 \mathrm{~h}$ light exposure and continued culture for $24 \mathrm{~h}^{12}$. The optimal concentration used to load A2E in human RPE cells is $25 \mu \mathrm{M}^{13}$. Based on this model, we further explored the effect of A2E on the levels of ROS and distributions of A2E in RPE cells to provide a basis for further study of the mechanism of retinal photodamage.

\section{Material And Methods}

\subsection{Cell sources and ethics statement}

Primary cultured RPE cells were isolated from three healthy men, aged 45,49 and 35, within $24 \mathrm{~h}$ of their accidental deaths. the eyes were taken after keratoplasty at the Affiliated Hospital of Zunyi Medical University. All experimentation adhered to the ethical standards established by the unit's Human Test Committee and approved by the Ethics Committee of Zunyi medical university, China ([2017]1-111).

\subsection{Patient involvement}

Patients were not directly involved in the design of this study.

\subsection{Reagents and instruments}

The following reagents and instruments were used: nifedipine (Sigma, Germany); a Reactive Oxygen Species Assay Kit (Beyotime, China); Dulbecco's modified Eagle medium/F12 (HyClone, USA); fetal bovine serum (HyClone, USA); trypsin-EDTA solution, 0.25\% (HyClone, USA); penicillin-streptomycin, liquid (Gibco, USA); LysoTracker Red DND-99 (Sigma, Germany); dimethyl sulfoxide (Solarbio, China); a DAB Substrate Kit (Zsbio Commerce Store, China); A2E (presented by the First Affiliated Hospital of Shanghai Jiaotong University); a medical blue light tube (Yingze, Tianjin); a high-speed tabletop centrifuge (Eppendorf, Germany); a Beckman Gallios flow cytometer (Beckman, USA); a Lysosome Isolation Kit (Invent, USA); and a Thermo U3000 Thermo Q Exactive Plus (Thermo, USA).

\subsubsection{Primary culture of human RPE cells}


Briefly, eye scissors were used to cut the eyeballs approximately $5 \sim 6 \mathrm{~mm}$ behind the corneal limb, and then the anterior segment was discarded. The vitreous body was removed, and the retinal neuroepithelium was carefully removed to isolate eye cups. The eye cups were digested with $0.25 \%$ trypsin for $30 \mathrm{~min}$ at $37^{\circ} \mathrm{C}$ in a $5 \% \mathrm{CO} 2$ atmosphere incubator. The cells were collected and resuspended in Dulbecco's modified Eagle's medium (DMEM) supplemented with $15 \%$ fetal bovine serum (FBS) and $1 \%$ penicillin/streptomycin. Then, the cells were cultured in a $25 \mathrm{~cm}^{2}$ culture flask at a density of $5 \times 10^{4}$ cells $/ \mathrm{ml}$ and kept at $37^{\circ}$ in $5 \% \mathrm{CO}^{2}$. The RPE cells were passaged at a ratio of $1: 2$, and cells at generation 4 6 were used for experiments. Each group comprised cells of the same generation from the same individual.

\subsubsection{Immunohistochemistry}

RPE cells were grown on glass coverslips coated with $0.01 \%$ polylysine. The cells were covered, fixed with precooled acetone for $10 \mathrm{~min}$ and incubated with $3 \%$ hydrogen peroxide for $15 \mathrm{~min}$. After three washes with distilled water, the cells were permeated with $1 \%$ Triton-X for 30 min at room temperature and washed again with PBS. Then, the cells were incubated with goat serum for $10 \mathrm{~min}$, followed by mouse anti-human RPE65 antibody overnight at $4^{\circ} \mathrm{C}$ and secondary goat anti-mouse $\lg \mathrm{G}$ antibodies for $1 \mathrm{~h}$ at $37^{\circ} \mathrm{C}$. Nuclei were stained with 4',6-diamidino-2-phenylindole (DAPI).

\subsubsection{Exposure of RPE cells to blue light and A2E treatment}

The human RPE cells from the fourth to sixth generation used for experiments were randomly divided into the following five groups: control group(CON), blue light group(BL), A2E-loaded group(A2E), A2E-loaded + blue light group $(\mathrm{A} 2 \mathrm{E}+\mathrm{BL})$, and $\mathrm{A} 2 \mathrm{E}-$ loaded + blue light + nifedipine group $(\mathrm{A} 2 \mathrm{E}+\mathrm{BL}+\mathrm{NIF})$. Before the cells were exposed to blue light, $A 2 E$ was diluted to a final concentration of $25 \mu \mathrm{M}$ in DMEM, and the cells were incubated with A2E for $2 \mathrm{~h}$ at $37^{\circ} \mathrm{C}$ and then washed three times to remove extracellular A2E. Nifedipine at a final concentration of $10^{-5} \mathrm{~mol} / \mathrm{L}$ was added $1 \mathrm{~h}$ before light exposure. Then, the RPE cells were exposed to blue light at an intensity of $2000 \pm 500$ lux for 6 hours, and the cells were cultured for 24 hours after exposure. Groups $A$ and $C$ were treated under the same conditions and wrapped in tin foil. Using a TES1330A illuminometer to measure the light intensity, the light intensity was adjusted by changing the distance between the culture flask or culture plate and the blue light tube.

\subsubsection{Reactive oxygen species (ROS) levels in human RPE cells}

After RPE cells were processed with blue light and A2E, they were washed twice with PBS, following which DCFH-DA diluted to a final concentration of $10 \mu \mathrm{M}$ in DMEM was added and incubated at $37^{\circ} \mathrm{C}$ for 20 minutes. Then, the cells were digested and centrifuged at $1000 \mathrm{rpm}$, the supernatant was discarded, and the pellet was resuspended in $300 \mu \mathrm{L}$ of PBS containing $3 \%$ calf serum at a density of $10^{6} \mathrm{cells} / \mathrm{ml}$. The ROS concentration was analyzed by flow cytometry with the pass band filter set at $488 \mathrm{~nm}$ for excitation, and the emission of DCFH was detected at $525 \mathrm{~nm}$. The data were analyzed with FlowJo software. In this experiment, the cells from 49 years old donor eyeball were used. 


\subsection{Isolation of cytoplasm and lysosomes}

After completing the treatment described above, the cells were collected and washed once with cold PBS. The supernatant was completely removed, and the pellet was resuspended in buffer $A$. The cell suspension was incubated on ice for $10 \mathrm{~min}$. The tube was vigorously vortexed for 20 seconds, following which the cell suspension was immediately transferred to the filter cartridge and centrifuged at $16000 \times \mathrm{g}$ for 30 seconds. Thee filter was discarded, and the pellet was resuspended by vigorous vortexing for 10 seconds. The sample was centrifuged at $2000 \times \mathrm{g}$ for $3 \mathrm{~min}$ (the pellet contained the nuclei, large cellular debris and some unruptured cells), and then all supernatant was transferred to a fresh $1.5 \mathrm{ml}$ microfuge tube and centrifuged at $4{ }^{\circ} \mathrm{C}$ for $15 \mathrm{~min}$ at $11000 \times \mathrm{g}$. The pellet contained mainly mitochondria and cellular debris. After centrifugation, the supernatant was carefully transferred to a fresh $1.5 \mathrm{ml}$ tube and spun at $16000 \times \mathrm{g}$ at $4^{\circ} \mathrm{C}$ for $30 \mathrm{~min}$. The supernatant consisting of the cytoplasm was collected.

In addition, the pellet was resuspended in cold buffer $A$ and centrifuged at $2000 \times \mathrm{g}$ for $4 \mathrm{~min}$. The supernatant was carefully transferred to a fresh $1.5 \mathrm{ml}$ tube. Buffer $B$ was added to the tube, which was vortexed briefly to mix well (the supernatant to buffer $B$ ratio was $2: 1$ ). The tube was incubated on ice for $30 \mathrm{~min}$ and centrifuged at $11000 \times \mathrm{g}$ for $10 \mathrm{~min}$. The supernatant was removed completely, and the pellet was a highly enriched lysosome fraction. The experiment used cells from the eyeballs of 35 years old donors.

\subsection{A2E levels in cytoplasm and lysosomes}

Methanol was added to the cytoplasm obtained as described above, and the mixture was centrifuged twice at $4{ }^{\circ} \mathrm{C}$ for $15 \mathrm{~min}$ at $16000 \times \mathrm{g}$. The supernatant was used for high-performance liquid chromatography-tandem mass spectrometry (HPLC-MS). A reverse-phase C18 column $(2.1 \times 50 \mathrm{~mm}, 1.7$ $\mu \mathrm{m}$, Waters, UK) was used for the entire HPLC analysis. The mobile phase consisted of a $0.1 \%$ formic acid-water solution and acetonitrile. The injection volume for each run was $5 \mu \mathrm{L}$. The samples were eluted at a flow rate of $0.4 \mathrm{ml} \mathrm{min-1.}$

Lysosomes obtained as described above were dissolved in ultrapure water, and methanol was then added to the suspension and centrifuged twice at $4{ }^{\circ} \mathrm{C}$ for $15 \mathrm{~min}$ at $16000 \times \mathrm{g}$. The supernatant was used for HPLC-MS, and the detection method was as above.

\subsection{A2E fluorescence in lysosomes}

The coverslips were placed in $35 \mathrm{~mm}$ culture dishes, and $100 \mu \mathrm{L}$ of cell suspension was added at a density of $10^{5}$ cells $/ \mathrm{ml}$ in $2 \mathrm{ml}$ of culture medium. After processing with blue light and A2E, the cells were washed twice with PBS. Then, LysoTracker red DND-99 at a final concentration of $50 \mathrm{nM}$ was added, and cells were stained in the dark for $20 \mathrm{~min}$ at $37^{\circ} \mathrm{C}$. Next, the RPE cells were fixed with $4 \%$ paraformaldehyde for $20 \mathrm{~min}$ and washed with PBS three times, and the cover slips were fixed on slides. The fluorescence intensity of A2E in lysosomes was observed and imaged using a Leica laser scanning confocal microscope. Cells from 35-year-old eyeball donor. 


\subsection{Statistical analysis}

These experiments were repeated at least 3 times. Data are expressed as the mean \pm standard deviation, and SPSS 18.0 software was applied to assess differences among groups with one-way analysis of variance followed by the least significant difference (LSD) test. Differences with a P-value $<0.05$ were considered statistically significant.

\section{Results}

\section{Human RPE cells and Immunohistochemistry}

Primary RPE cells were hexagonal or polygonal, and their cytoplasm was filled with pigment granules. After passage, the RPE cells were mostly fusiform or irregular, and the number of pigment granules in the cells was reduced. Immunofluorescence staining showed green fluorescence in RPE cells, indicating expression of RPE65. (Fig.1).

\section{Changes of ROS levels in human RPE cells}

The cells from 49 years old donor eyeball were used to probe the ROS levels. In the presence of ROS, intracellular DCFH is oxidized and fluoresces; therefore, ROS can be detected by measuring the fluorescence intensity due to DCF in cells. By flow cytometry, we determined the level of ROS, which was significantly different among groups; group $\mathrm{CON}$ which did not undergo treatment with A2E and blue light, exhibited the lowest level of ROS ( $P=0.000,0.011,0.000$, and 0.000 , respectively). We also found that ROS levels in groups $\mathrm{BL}, \mathrm{A} 2 \mathrm{E}+\mathrm{BL}$ and $\mathrm{A} 2 \mathrm{E}+\mathrm{BL}+\mathrm{NIF}$ were higher than those in group A2E ( $P=0.001,0.000$, and 0.000 , respectively). The ROS levels were significantly increased in groups $\mathrm{A} 2 \mathrm{E}+\mathrm{BL}$ and $\mathrm{A} 2 \mathrm{E}+\mathrm{BL}+\mathrm{NIF}$ when compared with group $\mathrm{BL}(P=0.000,0.000$, respectively), and the ROS levels in group $\mathrm{A} 2 \mathrm{E}+\mathrm{BL}+\mathrm{NIF}$ were lower than those in group $\mathrm{A} 2 \mathrm{E}+\mathrm{BL}(P=0.013)$ (Fig.2).

\section{A2E levels in the cytoplasm}

After exposure to blue light, the RPE cells which from 35 years old donor eyeball were cultured for 24 hours, detection and absolute quantitation of A2E via HPLC-MS, the molecular ion peak at $\mathrm{m} / \mathrm{z} 592$ corresponds to the molecular mass of A2E; there was almost no A2E in groups $\mathrm{CON}$ and BL. The levels of $A 2 E$ in group $A 2 E$ was found to be the highest compared with that in groups $A 2 E+B L$ and $A 2 E+B L+N I F$ $(P=0.000,0.000$, respectively). A2E levels in group $\mathrm{A} 2 \mathrm{E}+\mathrm{BL}+\mathrm{NIF}$ was lower than that in group A2E+BL $(P=0.020)$ (Fig.3).

\section{A2E levels in lysosomes}

The concentration of A2E in lysosomes was determined as described in the Materials and Methods section, the molecular ion peak at m/z 592 corresponds to the molecular mass of A2E, and there was almost no $A 2 E$ in groups $\mathrm{CON}$ and $\mathrm{BL}$. A2E levels in group A2E was significantly higher than that in groups $\mathrm{A} 2 \mathrm{E}+\mathrm{BL}$ and $\mathrm{A} 2 \mathrm{E}+\mathrm{BL}+\mathrm{NIF}(P=0.000,0.000$, respectively). The levels of $\mathrm{A} 2 \mathrm{E}$ in group $\mathrm{A} 2 \mathrm{E}+\mathrm{BL}$ was 
higher than that in group $\mathrm{A} 2 \mathrm{E}+\mathrm{BL}+\mathrm{NIF}(P=0.017)$ (Fig.4). The experiment used cells from the eyeballs of 35 years old donors.

5. A2E fluorescence in the lysosomes of RPE cells determined by laser scanning confocal microscopy

The green fluorescence due to A2E mostly overlapped with the red fluorescence of the lysosomes, indicating that most of the A2E had accumulated in lysosomes. Cells from 35-year-old eyeball donor (Fig.5).

\section{Discussion}

A2E is a major component of lipofuscin, which accumulates in the retinal pigment epithelial layer with age, and is also a substance believed to regulate blue light damage to the retina ${ }^{14}{ }^{15}$. The phototoxicity of blue light to RPE cells can cause changes in retinal cells, leading to retinal diseases, such as AMD, Stargardt's disease, and Best's disease ${ }^{16-20}$. Although the etiology of AMD remains unclear, AMD is known to be related to the accumulation of $A 2 E^{22122}$, the excessive absorption of retinol ${ }^{23}$, oxidative stress $^{24}$, and the inflammatory response ${ }^{25} 26$, and epigenetics ${ }^{27} 28$. Therefore, the established model of A2E-loaded RPE cells damaged with blue light can be used to explore retinal degenerative diseases.

In this experiment, human RPE cells were randomly divided into five groups. We found that ROS levels in the control group was the lowest, exposure to blue light or the addition of A2E could increase the production of ROS in RPE cells and that these stimuli acted synergistically. Calcium ions are an important second messenger in cells, and the mechanism of their messenger function is mainly realized by changes in their concentration. The addition of the calcium channel blocker nifedipine could inhibit the oxidative stress response of RPE cells, reduce intracellular ROS levels and protect RPE cells from apoptosis. These findings are consistent with the results of a study that showed that blue light could accelerate the oxidation of A2E in cells, trigger oxidative stress, produce large amounts of ROS, and induce apoptosis in RPE cells ${ }^{9}$.

Experimental studies on the relationship between A2E and lysosomes suggest that autophagy is involved in the accumulation of $A 2 E$ during lysosomal phagocytosis ${ }^{29} 30$. After the addition of $A 2 E$ to the cell culture medium, A2E was taken up by RPE cells and aggregated within these RPE cells, showing affinity for acidic organelles; this process was similar to the phagocytosis of A2E by RPE cell lysosomes ${ }^{31}$. Under exposure to light at a certain intensity for a certain length of time, A2E undergoes isomerization, during which free radicals are produced. In this experiment, the levels of A2E in the cytosol and lysosomes was determined via HPLC-MS. We found almost no A2E in the groups CON and BL, probably because $\mathrm{A} 2 \mathrm{E}$ was oxidized or metabolized in other ways with increasing cell passage. Changes of $\mathrm{A} 2 \mathrm{E}$ levels in other groups can be speculated that under blue light illumination, A2E is oxidized, producing an oxidative stress reaction. In this process, isomers or other oxidation products are formed, causing a significant decrease in the amount of total A2E. In addition, A2E can inhibit the proton pump function of lysosomes and further attack and destroy the lysosomal membrane, resulting in the leakage 
of $\mathrm{A} 2 \mathrm{E}$ or its oxidation products, which is more toxic ${ }^{32}{ }^{33}$. Furthermore, when RPE cells are exposed to blue light, the permeability of the lysosomal membrane in these RPE cells will be increased, which leads to the further leakage of A2E into the cytoplasm. And nifedipine can reduce calcium production and inhibit RPE cell apoptosis.

In summary, we detected intracellular ROS and A2E and found that blue light or A2E could increase the intracellular ROS levels of human RPE cells and that these stimuli had a synergistic effect. In this process, nifedipine could reduce the production of ROS and therefore had a protective effect on RPE cells. A2E is mainly concentrated in the lysosomes, and A2E in cytoplasm and lysosomes are reduced by oxidation under blue light irradiation, destroying lysosomal membrane with oxidized species of $A 2 E$, leaking out from lysosomes, initiating oxidative stress response that increases the production of ROS, causing damage to RPE cells.

\section{Declarations}

\section{Ethics approval and consent to participat}

This study was approved by the Ethics Committee of Zunyi medical university, China ([2017]1-111).

\section{Consent for publication}

Yes.

\section{Availability of data and material}

The datasets used and analyzed during the current study are available from the corresponding author on reasonable request.

\section{Competing interests}

The authors declare that they have no competing interests.

\section{Funding}

This work was supported by grant from the National Natural Science Foundation of China, 2017 [No. 81760174].

\section{Authors' contributions}

$\mathrm{ML}$ and $\mathrm{CZ}$ contributed equally to this work. These authors are co-first author. $\mathrm{ML}$ was responsible for some experiments and writing the manuscript. $\mathrm{CZ}$ had made significant contributions in experiments, data analysis, and writing manuscripts. SW had made significant contributions in some experiments. SC had made significant contributions in research conception and experimental design. All authors revised and approved the final version of the manuscript.

\section{Ackonwledges}


The author wishes to thank the Cell Engineering Laboratory and Anesthesia Laboratory of Zunyi Medical University, and Shanghai General Hospital (Shanghai First People's Hospital) of Shanghai Jiaotong University for their supply of experimental reagents.

\section{References}

1. Gordois A, Cutler H, Pezzullo L, et al. An estimation of the worldwide economic and health burden of visual impairment. Glob Public Health 2012;7(5):465-81. doi: 10.1080/17441692.2011.634815

2. Zhang J, Bai Y, Huang L, et al. Protective effect of autophagy on human retinal pigment epithelial cells against lipofuscin fluorophore A2E: implications for age-related macular degeneration. Cell Death Dis 2015;6:e1972. doi: 10.1038/cddis.2015.330

3. Lehmann GL, Benedicto I, Philp NJ, et al. Plasma membrane protein polarity and trafficking in RPE cells: past, present and future. Exp Eye Res 2014;126:5-15. doi: 10.1016/j.exer.2014.04.021

4. Di Lauro S, Rodriguez-Crespo D, Gayoso MJ, et al. A novel coculture model of porcine central neuroretina explants and retinal pigment epithelium cells. Mol Vis 2016;22:243-53.

5. Mihai DM, Washington I. Vitamin A dimers trigger the protracted death of retinal pigment epithelium cells. Cell Death Dis 2014;5:e1348. doi: 10.1038/cddis.2014.314

6. Zhao J, Liao Y, Chen J, et al. Aberrant Buildup of All-Trans-Retinal Dimer, a Nonpyridinium Bisretinoid Lipofuscin Fluorophore, Contributes to the Degeneration of the Retinal Pigment Epithelium. Invest Ophthalmol Vis Sci 2017;58(2):1063-75. doi: 10.1167/iovs.16-20734

7. Holz FG, Strauss EC, Schmitz-Valckenberg S, et al. Geographic atrophy: clinical features and potential therapeutic approaches. Ophthalmology 2014;121(5):1079-91. doi:

10.1016/j.ophtha.2013.11.023

8. Yakovleva MA, Feldman TB, Arbukhanova PM, et al. Estimation of fluorescence lifetime of lipofuscin fluorophores contained in lipofuscin granules of retinal pigment epithelium of human cadaver eyes without signs of pathology. Dokl Biochem Biophys 2017;472(1):19-22. doi:

$10.1134 /$ S1607672917010069

9. Wang Y, Kim HJ, Sparrow JR. Quercetin and cyanidin-3-glucoside protect against photooxidation and photodegradation of A2E in retinal pigment epithelial cells. Exp Eye Res 2017;160:45-55. doi:

10.1016/j.exer.2017.04.010

10. Zhao Z, Sun T, Jiang Y, et al. Photooxidative damage in retinal pigment epithelial cells via GRP78 and the protective role of grape skin polyphenols. Food Chem Toxicol 2014;74:216-24. doi: 10.1016/j.fct.2014.10.001

11. Apostolova N. ER stress in human hepatic cells treated with Efavirenz: mitochondria again. Hepatol 2013(59):780-89.

12. Su G, Cai SJ, Gong X, et al. Establishment of a blue light damage model of human retinal pigment epithelial cells in vitro. Genet Mol Res 2016;15(2) doi: 10.4238/gmr.15028092 
13. Lu B, Zhang P, Zhou M, et al. Involvement of XBP1s in Blue Light-Induced A2E-Containing Retinal Pigment Epithelium Cell Death. Ophthalmic Res 2017;57(4):252-62. doi: 10.1159/000452282

14. Pallitto $P, A b l o n c z y ~ Z$, Jones $E E$, et al. A2E and lipofuscin distributions in macaque retinal pigment epithelium are similar to human. Photochem Photobiol Sci 2015;14(10):1888-95. doi: 10.1039/c5pp00170f

15. Serezhnikova NB, Pogodina LS, Lipina TV, et al. Age-related adaptive responses of mitochondria of the retinal pigment epithelium to the everyday blue LED lighting. Dokl Biol Sci 2017;475(1):141-43. doi: 10.1134/S0012496617040044

16. Smith BT, Belani S, Ho AC. Ultraviolet and near-blue light effects on the eye. Int Ophthalmol Clin 2005;45(1):107-15.

17. Wenzel A, Grimm C, Samardzija M, et al. Molecular mechanisms of light-induced photoreceptor apoptosis and neuroprotection for retinal degeneration. Prog Retin Eye Res 2005;24(2):275-306. doi: 10.1016/j.preteyeres.2004.08.002

18. Algvere PV, Marshall J, Seregard S. Age-related maculopathy and the impact of blue light hazard. Acta Ophthalmol Scand 2006;84(1):4-15. doi: 10.1111/j.1600-0420.2005.00627.x

19. Boulton ME. Studying melanin and lipofuscin in RPE cell culture models. Exp Eye Res 2014;126:617. doi: 10.1016/j.exer.2014.01.016

20. Crouch RK, Koutalos Y, Kono M, et al. A2E and Lipofuscin. Prog Mol Biol Transl Sci 2015;134:44963. doi: $10.1016 /$ bs.pmbts.2015.06.005

21. Park SI, Lee EH, Kim SR, et al. Anti-apoptotic effects of Curcuma longa L. extract and its curcuminoids against blue light-induced cytotoxicity in A2E-laden human retinal pigment epithelial cells. J Pharm Pharmacol 2017;69(3):334-40. doi: 10.1111/jphp.12691

22. Anderson OA, Finkelstein A, Shima DT. A2E induces IL-1ss production in retinal pigment epithelial cells via the NLRP3 inflammasome. PLoS One 2013;8(6):e67263. doi:

10.1371/journal.pone.0067263

23. Farjo KM, Farjo RA, Halsey S, et al. Retinol-binding protein 4 induces inflammation in human endothelial cells by an NADPH oxidase- and nuclear factor kappa B-dependent and retinolindependent mechanism. Mol Cell Biol 2012;32(24):5103-15. doi: 10.1128/MCB.00820-12

24. Kauppinen A, Niskanen H, Suuronen T, et al. Oxidative stress activates NLRP3 inflammasomes in ARPE-19 cells-implications for age-related macular degeneration (AMD). Immunol Lett 2012;147(12):29-33. doi: 10.1016/j.imlet.2012.05.005

25. Bergmann M, Schutt F, Holz FG, et al. Inhibition of the ATP-driven proton pump in RPE lysosomes by the major lipofuscin fluorophore A2-E may contribute to the pathogenesis of age-related macular degeneration. FASEB J 2004;18(3):562-4. doi: 10.1096/fj.03-0289fje

26. Nociari MM, Lehmann GL, Perez Bay AE, et al. Beta cyclodextrins bind, stabilize, and remove lipofuscin bisretinoids from retinal pigment epithelium. Proc Natl Acad Sci US A 2014;111(14):E1402-8. doi: 10.1073/pnas.1400530111 
27. Chen $Y$, Yang P, Li F, et al. The effects of Th17 cytokines on the inflammatory mediator production and barrier function of ARPE-19 cells. PLoS One 2011;6(3):e18139. doi:

10.1371/journal.pone.0018139

28. Hunter A SP, Cwanger A. DNA methylation is associated with altered gene expression in AMD. Invest Ophthalmol Vis Sci 2012(52):5980.

29. Perusek L, Sahu B, Parmar T, et al. Di-retinoid-pyridinium-ethanolamine (A2E) Accumulation and the Maintenance of the Visual Cycle Are Independent of Atg7-mediated Autophagy in the Retinal Pigmented Epithelium. J Biol Chem 2015;290(48):29035-44. doi: 10.1074/jbc.M115.682310

30. Guha S, Liu J, Baltazar G, et al. Rescue of compromised lysosomes enhances degradation of photoreceptor outer segments and reduces lipofuscin-like autofluorescence in retinal pigmented epithelial cells. Adv Exp Med Bio/ 2014;801:105-11. doi: 10.1007/978-1-4614-3209-8_14

31. Ramkumar HL, Zhang J, Chan CC. Retinal ultrastructure of murine models of dry age-related macular degeneration (AMD). Prog Retin Eye Res 2010;29(3):169-90. doi: 10.1016/j.preteyeres.2010.02.002

32. Sparrow JR, Parish CA, Hashimoto M, et al. A2E, a lipofuscin fluorophore, in human retinal pigmented epithelial cells in culture. Invest Ophthalmol Vis Sci 1999;40(12):2988-95.

33. Schutt F, Bergmann M, Holz FG, et al. Isolation of intact lysosomes from human RPE cells and effects of A2-E on the integrity of the lysosomal and other cellular membranes. Graefes Arch Clin Exp Ophthalmol 2002;240(12):983-8. doi: 10.1007/s00417-002-0558-8

\section{Figures}

\section{Figure 1}

A. Primary human RPE cells. B. Third-generation human RPE cells. C. Primary mouse anti-human RPE65 antibody and secondary goat anti-mouse IgG antibodies were used to immunostain the third generation RPE cells. Immunofluorescence staining was positive for RPE65. 

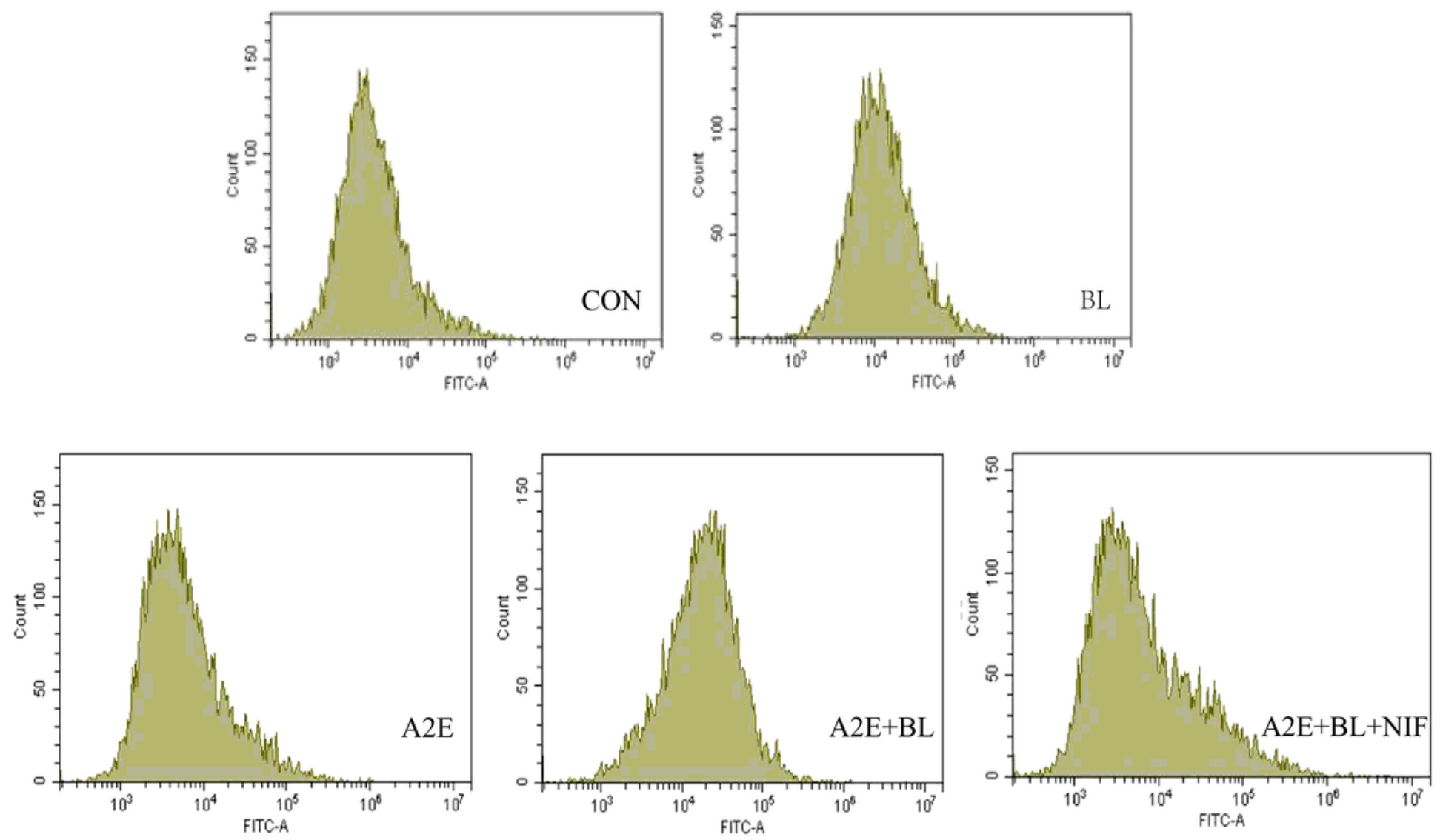

A

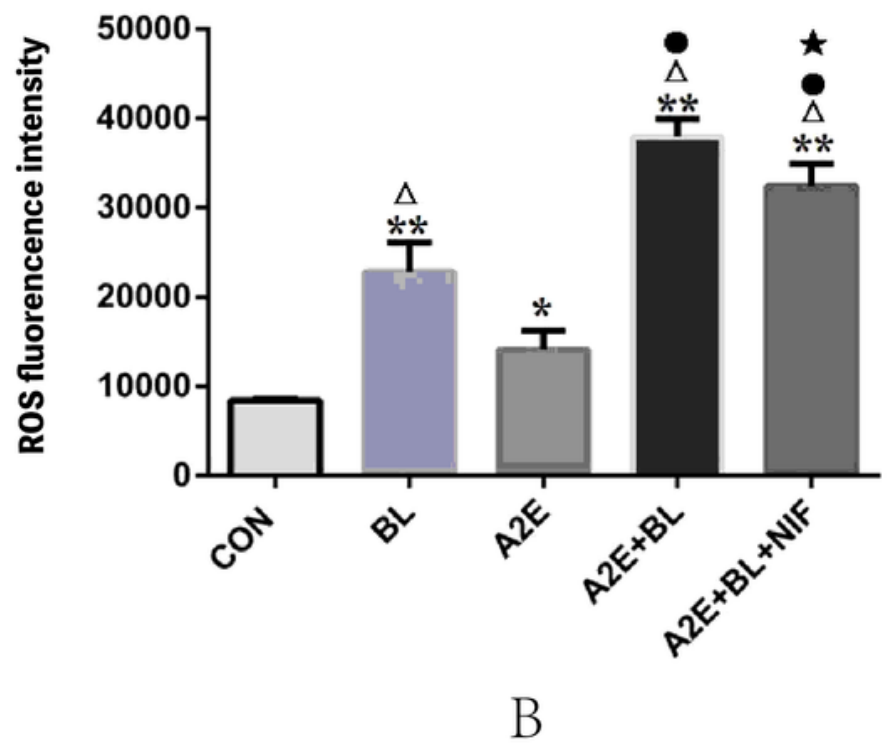

Figure 2

A. Since the fluorescence spectrum of DCF was similar to that of FITC, the parameter setting of FITC was used to detect DCF. B. ${ }^{*}<<0.05$ or ${ }^{* *} p<0.01$ statistically significant compared with the group CON; $\Delta p<$ 0.001 statistically significant compared with the group $A 2 E ; \cdot p<0.001$ statistically significant compared with the group $B L ; \otimes p<0.05$ compared with the group $A 2 E+B L$. 

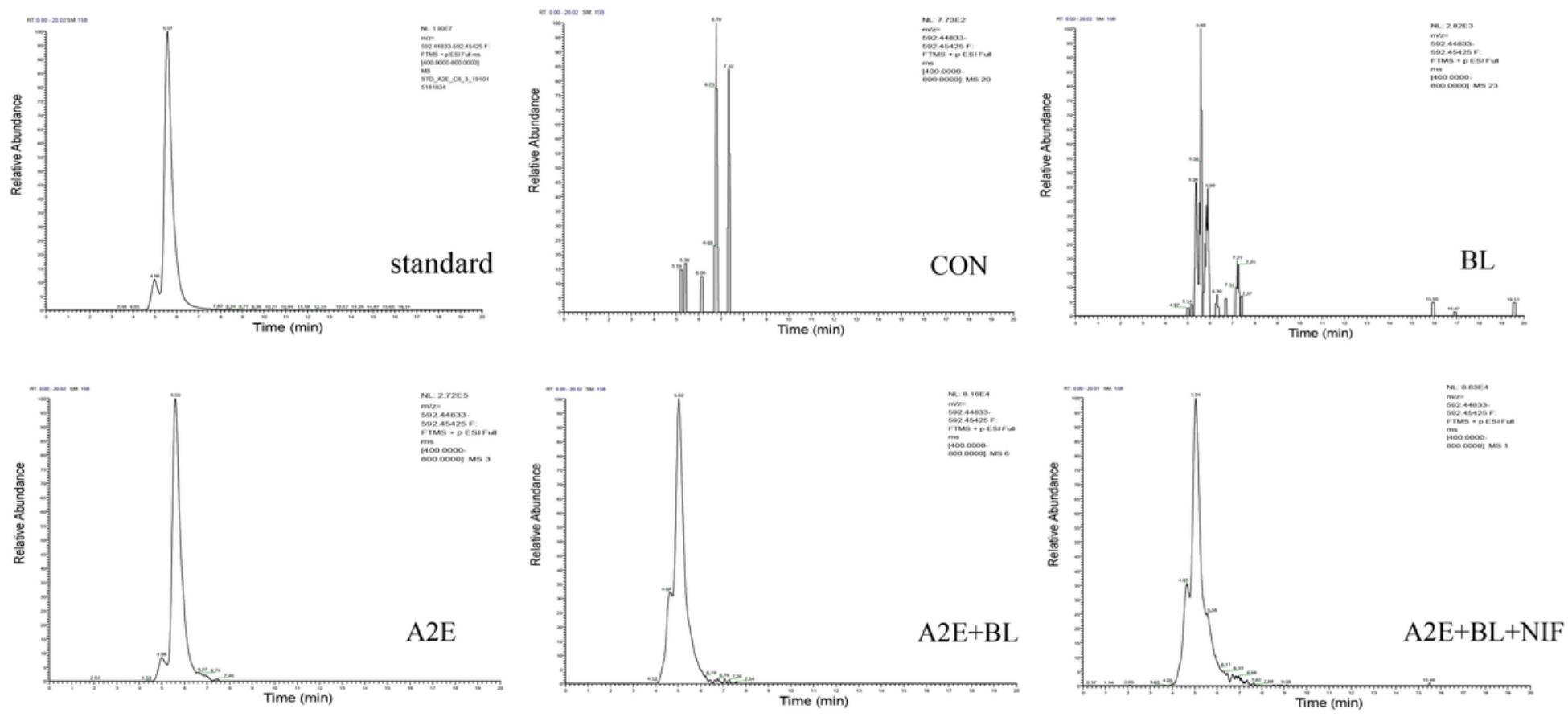

A

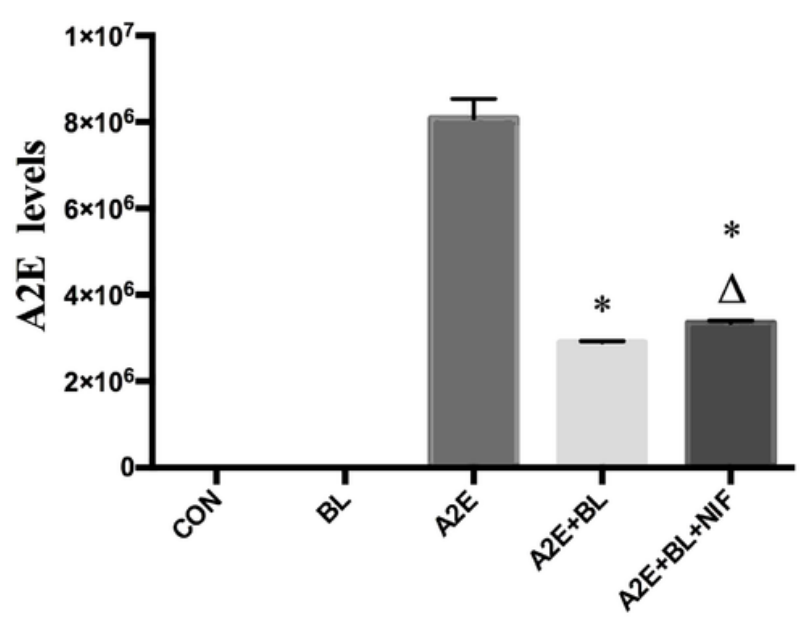

B

\section{Figure 3}

A. Extracted ion chromatogram of $\mathrm{m} / \mathrm{z} 592.5$. The levels of $A 2 E$ in the cytoplasm was reduced after blue light irradiation. B. ${ }^{*} p<0.001$ statistically significant compared with the group A2E; $\Delta p<0.05$ statistically significant compared with the group $\mathrm{A} 2 \mathrm{E}+\mathrm{BL}$. 

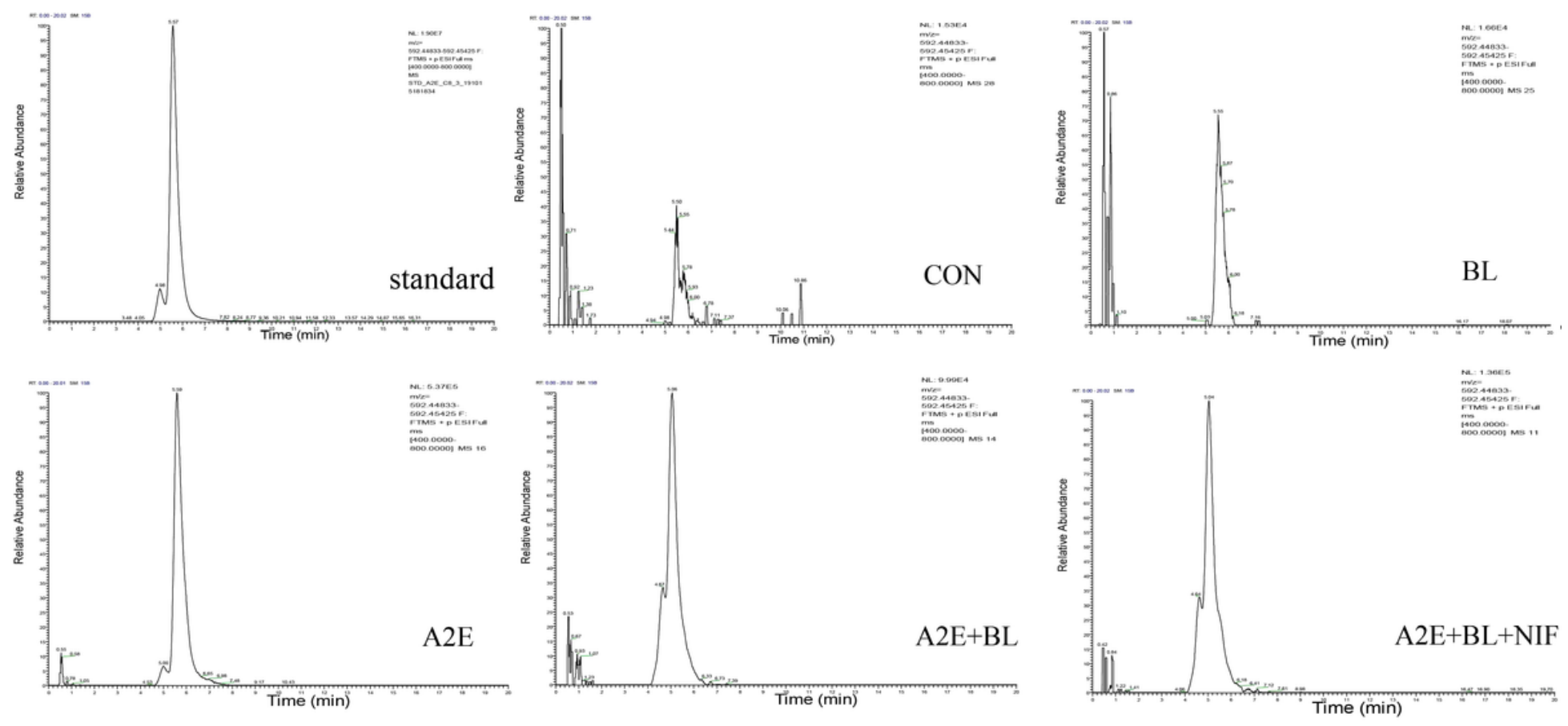

A

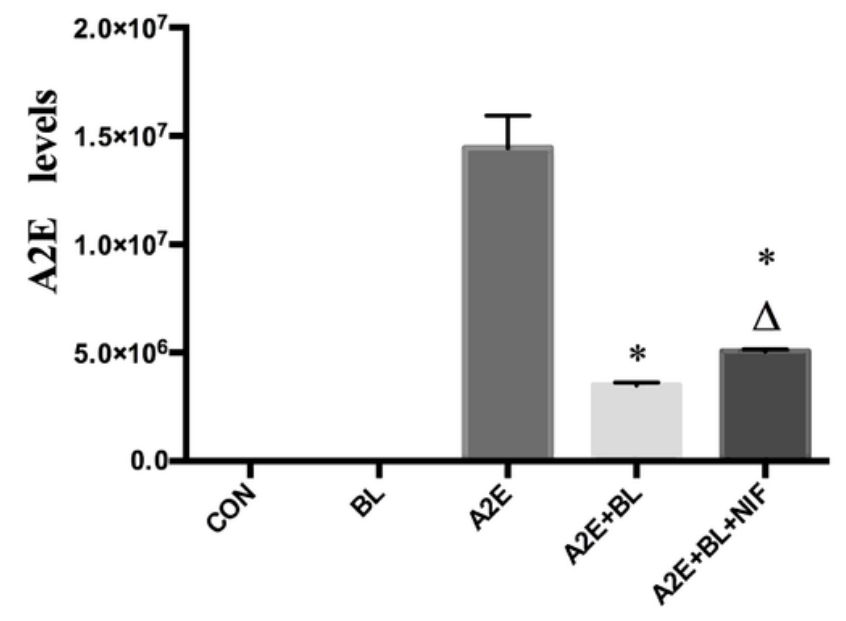

B

Figure 4

A. The extracted ion chromatogram from the mass spectrometry analysis of $A 2 E(m / z 592)$. The levels of A2E in lysosomes was decreased after exposure to blue light. B. ${ }^{*} \mathrm{p}<0.001$ statistically significant compared with the group A2E; $\Delta p<0.05$ statistically significant compared with the group A2E+BL. 


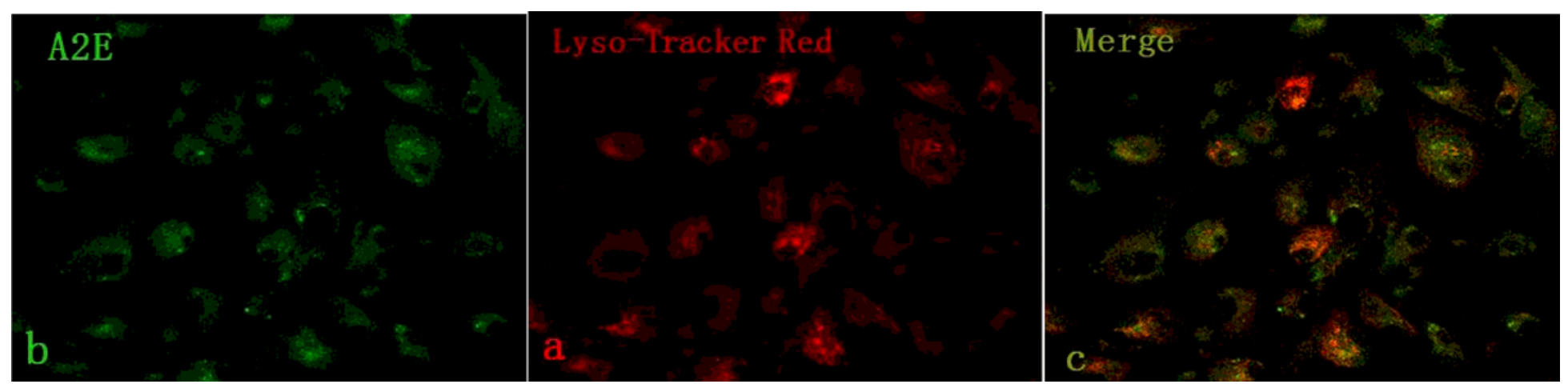

\section{Figure 5}

A. Lysosomes labeled with Lysotracker red DND-99. B. A2E in lysosomes. C. Merge of the images in A. and $\mathrm{B}$. 